\title{
Transcutaneous Drug Delivery Systems Based on Collagen/Polyurethane Composites Reinforced with Cellulose
}

\author{
Narcis Anghel ${ }^{1, *(\mathbb{D}}$, Valentina Maria Dinu ${ }^{1}\left(\mathbb{D}\right.$, Liliana Verestiuc ${ }^{2} \mathbb{D}$ and Irene Alexandra Spiridon ${ }^{2}$ \\ 1 “Petru Poni" Institute of Macromolecular Chemistry, Grigore Ghica-Voda 41, 700487 Iasi, Romania; \\ vdinu@icmpp.ro \\ 2 Faculty of Medicine, Grigore T. Popa University of Medicine and Pharmacy, 9-13 Kogalniceanu Street, \\ 700454 Iasi, Romania; liliana.verestiuc@bioinginerie.ro (L.V.); irenespiridon@yahoo.com (I.A.S.) \\ * Correspondence: anghel.narcis@icmpp.ro
}

check for updates

Citation: Anghel, N.; Dinu, V.M.; Verestiuc, L.; Spiridon, I.A. Transcutaneous Drug Delivery Systems Based on Collagen/ Polyurethane Composites Reinforced with Cellulose. Polymers 2021, 13, 1845. https://doi.org/10.3390/ polym13111845

Academic Editor: Fernão D. Magalhães

Received: 20 April 2021

Accepted: 26 May 2021

Published: 2 June 2021

Publisher's Note: MDPI stays neutral with regard to jurisdictional claims in published maps and institutional affiliations.

Copyright: (c) 2021 by the authors. Licensee MDPI, Basel, Switzerland. This article is an open access article distributed under the terms and conditions of the Creative Commons Attribution (CC BY) license (https:// creativecommons.org/licenses/by/ $4.0 /)$.

\begin{abstract}
Designing composites based on natural polymers has attracted attention for more than a decade due to the possibility to manufacture medical devices which are biocompatible with the human body. Herein, we present some biomaterials made up of collagen, polyurethane, and cellulose doped with lignin and lignin-metal complex, which served as transcutaneous drug delivery systems. Compared with base material, the compressive strength and the elastic modulus of biocomposites comprising lignin or lignin-metal complex were significantly enhanced; thus, the compressive strength increased from 61.37 to $186.5 \mathrm{kPa}$, while the elastic modulus increased from 0.828 to $1.928 \mathrm{MPa}$. The release of ketokonazole from the polymer matrix follows a Korsmeyer-Peppas type kinetics with a Fickian diffusion. All materials tested were shown to be active against pathogenic microorganisms. The mucoadhesiveness, bioadhesiveness, mechanical resistance, release kinetic, and antimicrobial activity make these biocomposites to be candidates as potential systems for controlled drug release.
\end{abstract}

Keywords: collagen; polyurethane; cellulose; lignin; composites; drug release

\section{Introduction}

The beginning of the third millennium undoubtedly presents itself as a milestone in technological development. In a relatively short time, high-tech industries have shown an almost exponential development at the same time as the formulation of new concepts and theories. Thus, the reorientation is somewhat surprising, given the emergence of new intelligent materials for the use of natural products in different areas of activity that interfere with the biological field.

Natural polymers, given their intrinsic nature, are best suited for a wide variety of biomedical applications. Biodegradability and biocompatibility are key aspects for the formulation of drug delivery systems or for cell therapies such as wound dressing or their use as scaffolds for tissue engineering [1-4]. Herein, for the solubilization of cellulose, collagen, and polyurethane, in order to obtain transcutaneous transfer systems, a so-called green solvent was used which belonged to the category of ionic liquids, namely 1-(n-butyl)3-methylimidazolium chloride [5]. The reason why the polymeric materials mentioned above were chosen for the design of topical composites for drug delivery devices was the fact that collagen ensures the bioadhesion of the material on the skin, polyurethane gives the necessary elasticity to the patches, and cellulose is a reinforcing material for the assurance of the mechanical strength.

Cellulose is one of the most widespread vegetable semicrystalline polymers, consisting of glucose units coupled by $\beta-1,4$-glucoside bonds [6]. Due to its hydrophilicity, it has a good absorption capacity, and for to its biocompatibility with the animal body, it is recommended for various biomedical or cosmetic applications [7-9]. 
At the same time, cellulose derivatives have proven to be versatile materials with multiple applications in a wide range of fields. Thus, cellulose derivatives have found their use in making seedling pots [10], surgical sutures [11,12], patches for topical applications [13-15], or for the design of biofriendly materials that have proven effective for heavy-metal retention [16-20]. The emergence of nanostructured biomaterials has paved the way for the design of cellulose-based composites for the controlled transport of drugs or other bioactive principles [21-25].

Collagen is probably the most abundant protein in the animal kingdom, forming the constitution of connective tissue, bones, tendons, and ligaments. For our studies, we considered type I collagen to be a component for composite transcutaneous transport systems due to its triple-helical structure that gives it a fibrillar morphology that has elasticity and mechanical strength. Cellulose/collagen composites have found successful applications in tissue engineering due to their biocompatibility with the human body $[26,27]$.

Polyurethanes have proven to be interesting candidates for composite biomaterials used in vascular implants and grafts due to their biocompatibility with human body tissues [28-32]. In the same context, poly (ester-urethane)-containing phosphorylcholine segments have been shown to improve the hemocompatibility of blood-contacting medical devices [33]. On the other hand, the fine-tuning of the polyurethane structure allowed the design of materials with controlled biodegradability for long-term implant application [34,35]. Cellulose/polyurethane elastomers with good mechanical strength have proven to be high-performance and effective materials for wound treatment [36].

The incorporation of some drugs in the polymer matrix and their controlled release is an important way to control infections, inflammation, or tissue regeneration.

Lignin, probably the most widespread aromatic polymer of vegetable nature, has, among other things, important antioxidant properties, which make it attractive in terms of potential applications for the treatment of skin diseases [37-40]. At the same time, data from the literature stipulate the ability of lignin and ketoconazole to form complexes with some transition metals [41].

Thus, the biocomposites obtained were doped with a lignin or lignin-metal complex, which confers to these materials, the ability to control, through a large specific surface area and complexation capacity, the release of drugs with fungicidal properties such as ketoconazole.

Considering the interactions between the components of the matrix, lignin, and ketoconazole, the obtained materials were studied in terms of in vitro drug release, mucoadhesiveness and biological activity against pathogenic microorganisms. At the same time, morphology, mechanical properties, and interactions between system components were studied by scanning electron microscopy (SEM), compression tests, and Fourier transform infrared spectroscopy (FTIR).

\section{Materials and Methods}

\subsection{Materials}

Cellulose (cotton linters, $\sim 20$ micrometers, $240 \mathrm{Da}$ ), collagen hydrolysate, a polypeptide made by further hydrolysis of denatured collagen (molecular weight of $96 \mathrm{kDa}$ ), $\beta$-cyclodextrine, methylene diphenyl diisocyanate, and polycaprolactone $\left(M_{n} \sim 2000\right)$ were purchased from Sigma-Aldrich and used without further purification. Ketokonazole was from Supelco, and organic lignin was extracted with acetic acid/phosphinic acid from birch wood [42].

\subsection{Methods}

\subsubsection{Polyurethane Synthesis}

The polyurethanes used in this study were synthesized from polycaprolactone (PCL), methylene diphenyl diisocyanate (MDI), and a mixture of butane diol (BD) and betacyclodextrin $(\beta-C D)$ at ratio of $9 / 1(w / w)$, as chain extender in DMF solution. In brief, the PCL was dried in vacuum $1 \mathrm{~mm} \mathrm{Hg}$ at $80^{\circ} \mathrm{C}$ for $3 \mathrm{~h}$. The reaction was carried out under 
stirring with MDI at the temperature of $80^{\circ} \mathrm{C}$ for $1 \mathrm{~h}$, and then the DMF solution mixture of $\mathrm{BD}$ and $\beta-\mathrm{CD}$ were added, and the mass reaction was kept under stirring at $60{ }^{\circ} \mathrm{C}$ for $6 \mathrm{~h}$. The polyaddition reaction was stopped with a solution of $5 \mathrm{~mL} \mathrm{EtOH:DMF} \mathrm{1:1} \mathrm{(v/v)} \mathrm{at}$ the viscosity of $\sim 7000 \mathrm{cP}$. Molar ratio between components was PCL/MDI/(BD/ $\beta-\mathrm{CD})$ of $3 / 4 / 1$ [43].

\subsubsection{Preparation of Biomaterials}

The reference material CCP (cellulose-collagen-polyurethane) was obtained by dissolution of cellulose $(1 \mathrm{~g})$, collagen $(0.25 \mathrm{~g})$, and polyurethane $(0.25 \mathrm{~g})$ in buthyl-3-methylimidazolium chloride $(10 \mathrm{~g})$ under stirring, at temperature of $100{ }^{\circ} \mathrm{C}$ for $8 \mathrm{~h}$. Other biomaterials named CCPK (cellulose-collagen-polyurethane-ketoconazole), CCPOLK (cellulosecollagen-polyurethane-organosolv lignin-ketoconazole), CCPLMCK (cellulose-collagenpolyurethane-lignin metal complex-ketoconazole), CCPOL (cellulose-collagen-polyurethaneorganosolv lignin), and CCPLMC (cellulose-collagen-polyurethane-lignin metal complex) were obtained by addition of $0.15 \mathrm{~g}$ lignin or lignin-ferrite hybrid (obtained in our laboratory by combustion of lignin with cobalt nitrate $\mathrm{Co}\left(\mathrm{NO}_{3}\right)_{2} 6 \mathrm{H}_{2} \mathrm{O}$ and ferric nitrate $\mathrm{Fe}\left(\mathrm{NO}_{3}\right)_{3}$ $9 \mathrm{H}_{2} \mathrm{O}$ at $500{ }^{\circ} \mathrm{C}$ ) and $0.15 \mathrm{~g}$ ketoconazole to the cellulose-collagen-polyurethane matrix, by case. Biocomposites were obtained by casting in Petri dishes. After $48 \mathrm{~h}$, the samples were washed with distilled water and dried.

\subsection{Characterization}

\subsubsection{FTIR Spectroscopy}

FTIR spectroscopy was used to analyze the possible interactions materials' components. In total, 64 scans of all samples were acquired using a Bruker, Vertex 70 (Billerica, MA, USA) ATR-FTIR spectrometer, equipped with ATR device (ZnSe crystal) with a 45 angle of incidence. The scan was recorded in a range from 4000 to $600 \mathrm{~cm}^{-1}$ and a spectral resolution of $2 \mathrm{~cm}^{-1}$.

\subsubsection{Scanning Electron Microscopy}

SEM was used to analyze the cross-sections of material using a SEM (FEI QUANTA 200ESEM instrument) with an integrated EDX system, GENESIS XM2i EDAX with an SUTW detector. The samples were analyzed with a low-vacuum secondary electron detector at an accelerating voltage of $25.0 \mathrm{kV}$, at room temperature, and 0.050 Torr internal pressure. The experiment was performed in triplicate, at a magnification of $10,000 \times$.

\subsection{Bioadhesivity Test}

An TA.XT plus ${ }^{\circledR}$ analyzer from Stable Micro Systems (Godalming, UK) was used to evaluate the adhesion force (maximum detachment force) and total work of adhesion. The bioadhesion tests were performed on cellulose dialysis membrane, preboiled and cooled before testing, in a physiologically simulated environment of $37^{\circ} \mathrm{C}$, with a $\mathrm{pH}$ of 7.4 value (100 $\mu \mathrm{L}$ PBS added to each probe) and $250 \mathrm{rpm}$. The mucoadhesion tests were performed on porcine small intestine (bowel), in a physiologically simulated environment of $37^{\circ} \mathrm{C}$, with a $\mathrm{pH}$ of 7.4 value (100 $\mu \mathrm{L}$ PBS added to each probe) and $250 \mathrm{rpm}$.

\subsection{Compression Test}

The mechanical properties were investigated on EZ-LX/EZ-SX Series Shimadzu Testing Machine (Kyoto, Japan) in compression mode. All measurements were performed at room temperature, and the hydrogel samples were tested in swollen state after immersion in PBS. For compressive stress, the hydrogel samples were shaped as plate specimens with the thickness of $9 \mathrm{~mm}$, width of $12 \mathrm{~mm}$, and height of $2 \mathrm{~mm}$. Before each measurement, an initial force of $0.1 \mathrm{~N}$ was applied to the hydrogel samples to ensure the complete contact between entire biomaterial surfaces and the parallel compression plates of the testing equipment. For each hydrogel sample, three measurements were registered at a cross-head speed of $1 \mathrm{~mm} \mathrm{~min}^{-1}$, and the values of Young modulus were presented as an average 
value $\pm \mathrm{SD}$. The force applied was kept constant for all samples at $100 \mathrm{~N}$. The compressive stress $(\sigma, \mathrm{kPa})$ was calculated as the normal force acting perpendicular to the area of the un-deformed specimen, whereas the strain $(\varepsilon)$ was expressed as the ratio between the deformed and initial length of the hydrogel sample.

\subsection{In Vitro Release Studies}

The experiments were carried out in phosphate buffer saline (PBS) pH 7.2 at $37 \pm 0.5^{\circ} \mathrm{C}$. Aliquotes of $0.5 \mathrm{~mL}$ of the supernatant were removed at different time intervals and diluted to a total volume of $3 \mathrm{~mL}$, prior to examination. The amount taken was replaced with fresh PBS in order to maintain the sink conditions. The concentration of the released ketoconazole was analyzed spectrophotometrically at $\lambda_{\max }$ value of $254 \mathrm{~nm}$, at room temperature. The concentrations were calculated based on the calibration curves determined at the same wavelength. The drug-release kinetics was evaluated using the equation proposed by Korsmeyer and Peppas (Equation (1)) [44].

$$
\frac{M_{t}}{M_{\infty}}=k \times t^{n}
$$

where $M_{t} / M_{\infty}$ represents the fraction of the drug released at time $t ; M_{t}$ and $M_{\infty}$ are the absolute cumulative amount of drug released at time $t$ and the maximum amount released in the experimental conditions used, at the plateau of the release curves; $\mathrm{k}$ is a constant incorporating the characteristics of the macromolecular drug loaded system; and $n$ is the release exponent, which is indicative of the release mechanism.

In the equation above, a value of $n<0.5$ indicates a Fickian diffusion mechanism of the drug from the biomaterial sample, while a value $0.5<n<1$ indicates a non-Fickian behavior. When $n=1$, a case II transport mechanism is involved with zero order kinetics, while $n>1$ indicates a special case II transport mechanism [45].

\subsection{Antimicrobial Activity}

Culture media were prepared from Salmonella typhymurium, Escherichia coli 25,922, and Candida albicans strains in peptone saline with a turbidity of $1^{\circ}$ McFarland. A suspension of approximately 1500 UFC (colony-forming units $/ \mathrm{mL}$ ) was obtained by dilution. The surface of the tested materials, as well as of the control, was contaminated with $100 \mu \mathrm{L}$ ATCC strain (Salmonella typhymurium 14,028, Escherichia coli 25,922, and Candida albicans). The inoculate was extracted using a sterile swab soaked in peptone saline and seeded on the surface of the specific environment (XLD, VRBG, and ALOA) after $24 \mathrm{~h}$, and the plates were incubated at $37 \pm 1{ }^{\circ} \mathrm{C}$ for $24 \mathrm{~h}$. The colonies were counted, and the values were compared to the control.

\section{Results and Discussions}

\subsection{FTIR Analysis}

FTIR spectroscopy was used to analyze the possible interactions between material components.

Figure 1 depicts the FTIR spectra for components of the reference film. The peaks observed in cellulose spectra (Figure 1a), in the range of $3660-2900 \mathrm{~cm}^{-1}$, are characteristic for the stretching vibration of $\mathrm{O}-\mathrm{H}$ and $\mathrm{C}-\mathrm{H}$ bonds in polysaccharides, while the broad peak at $3334 \mathrm{~cm}^{-1}$ is characteristic for the stretching vibration of the hydroxyl group in polysaccharides [46]. The band at $2900 \mathrm{~cm}^{-1}$ is attributed to the $\mathrm{C}-\mathrm{H}$ stretching vibration of all hydrocarbon constituents in polysaccharides. Typical bands assigned to cellulose were observed in the region of $1630-900 \mathrm{~cm}^{-1}$. The peaks located at $1631 \mathrm{~cm}^{-1}$ correspond to the vibration of water molecules absorbed in cellulose [47]. The absorption bands at $1427,1367,1334,1029$, and $898 \mathrm{~cm}^{-1}$ belong to the stretching and bending vibrations of $-\mathrm{CH}_{2}$ and $-\mathrm{CH},-\mathrm{OH}$ and $\mathrm{C}-\mathrm{O}$ bonds in cellulose $[48,49]$. 


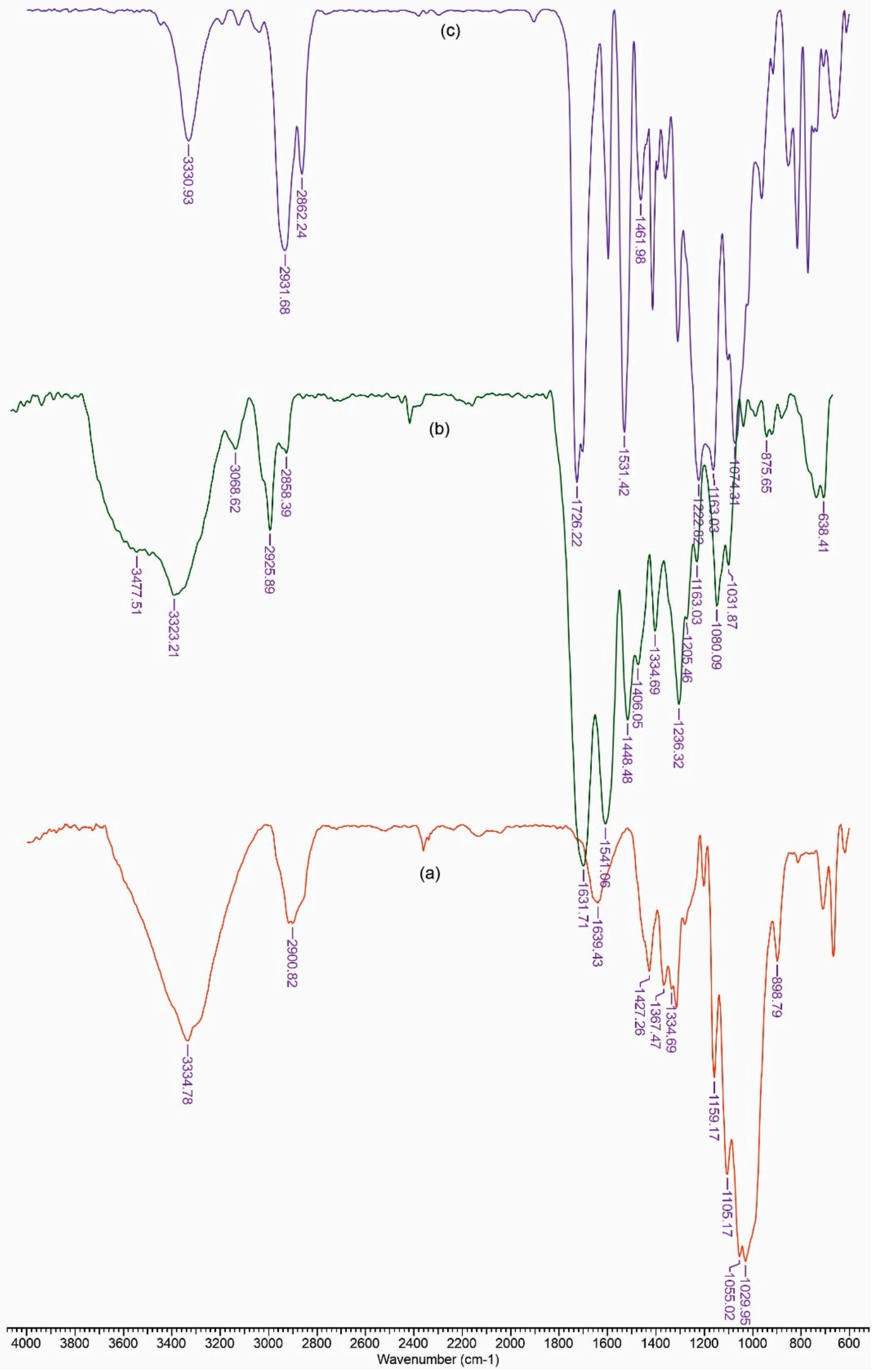

Figure 1. FTIR spectrum for cellulose (a), polyurethane (b) and collagen (c). 
Figure $1 \mathrm{~b}$ shows the Fourier transform infrared spectrum recorded for polyurethane. The absorption band at $3323 \mathrm{~cm}^{-1}$ corresponds to NH stretching. The sharp peaks at 2858 and $2925 \mathrm{~cm}^{-1}$ are associated with $-\mathrm{CH}_{2}$ stretching, while other modes of $-\mathrm{CH}_{2}$ vibrations are identified by the bands at $1448,1406,1334$, and $1236 \mathrm{~cm}^{-1}$. In addition, the absorption band at $1631 \mathrm{~cm}^{-1}$ is associated with a $\mathrm{C}=\mathrm{O}$ group in polyurethane. The group of $\mathrm{NH}$ bend vibrations is identified by the band at $1631 \mathrm{~cm}^{-1}$ [50].

The spectra of collagen (Figure 1c) shows the amide A band, associated with $\mathrm{N}-\mathrm{H}$ stretching, at $3330 \mathrm{~cm}^{-1}$. The amide bands were observed at 1631, 1541 and $1334 \mathrm{~cm}^{-1}$, respectively. Polypeptide backbone $\mathrm{C}-\mathrm{O}$ stretching vibration was found in the range of $1600-1700 \mathrm{~cm}^{-1}$. C-N stretching vibrations were noted at $1222 \mathrm{~cm}^{-1}$ [51].

In Figures 2 and 3 FTIR spectra are presented for the obtained materials. The spectra data show absorption bands characteristic for amino or carboxy groups that overlap with those of the vibration spectra in cellulose. The usefulness of these spectra lies in the fact that it allows the calculation of some structural parameters, as can be seen below.

Based on the recorded spectra, we can calculate a series of indices that reflect the degree of ordering and the total crystallinity, as well as the strength of the hydrogen bonds, for the studied materials.

The ratio between the heights of the bands at 1376 and $2902 \mathrm{~cm}^{-1}$ was proposed by Colomn and Carrillo [52] as the total crystalline index (TCI). The band at $1437 \mathrm{~cm}^{-1}$ is associated with the crystalline structure of cellulose, while the band at $899 \mathrm{~cm}^{-1}$ is assigned to the amorphous region in the cellulose. The ratio between the absorbance of the bands at 1437 and $899 \mathrm{~cm}^{-1}$ is used as a lateral order index (LOI). Considering the chain mobility and bond distance, the hydrogen bond intensity (HBI) of cellulose is closely related to the crystal system and the degree of intermolecular regularity-that is, crystallinity. The ratio of the absorbance bands at 3336 and $1336 \mathrm{~cm}^{-1}$ was used to study the cellulose sample's HBI. The obtained results are displayed in Table 1 . The TCI is proportional to the degree of crystallinity of cellulose, and LOI represents the ordered regions perpendicular to the chain direction in the cellulose.

Table 1. Total crystalline index (TCI), lateral order index (LOI), and hydrogen bound intensity (HBI) values obtained from the FTIR spectra analysis of the biocomposites.

\begin{tabular}{cccc}
\hline Sample & TCI $\left(\mathbf{A}_{\mathbf{1 3 7 6}} / \mathbf{A}_{\mathbf{2 9 0 2}}\right)$ & HBI $\left(\mathbf{A}_{\mathbf{3 3 3 6}} / \mathbf{A}_{\mathbf{1 3 3 6}}\right)$ & LOI $\left(\mathbf{A}_{\mathbf{1 4 3 7}} / \mathbf{A}_{\mathbf{8 9 9}}\right)$ \\
\hline Cellulose & 1.844 & 5.140 & 2.174 \\
\hline CCPK & 1.625 & 4.114 & 2.849 \\
\hline CCPOLK & 1.143 & 6.148 & 4.557 \\
\hline CCPLMCK & 1.855 & 4.637 & 3.333 \\
\hline CCP & 1.901 & 3.620 & 1.842 \\
\hline CCPOL & 1.870 & 3.969 & 1.979 \\
\hline CCPLMC & 1.436 & 3.985 & 1.836 \\
\hline
\end{tabular}

CCPK-cellulose-collagen-polyurethane-ketoconazole; CCPOLK-cellulose-collagen-polyurethane-organosolv lignin-ketoconazole; CCPLMCK—cellulose-collagen-polyurethane-lignin metal complex-ketoconazole; CCPcellulose-collagen-polyurethane; CCPOL—cellulose-collagen-polyurethane-organosolv lignin; and CCPLMCcellulose-collagen-polyurethane-lignin metal complex.

The CCP samples exhibited the highest TCI and a low LOI, which implies the highest crystallinity degree and an increase in ordered regions perpendicular to the chain direction in cellulose. The data from Table 1 show that the CCPOLK material presents the highest LOI and a low value of TCI. It is possible that a lateral ordered cellulose structure was obtained in the cellulose-collagen-polyurethane matrix by the addition of organic lignin along with ketoconazole. At the same time, the HBI value for CCPOLK and CCPLMCK increased as compared to that of the matrix, which means that fewer available hydroxyl groups in the cellulose chain are able to interact by inter- and/or intra-molecular hydrogen bonding. 


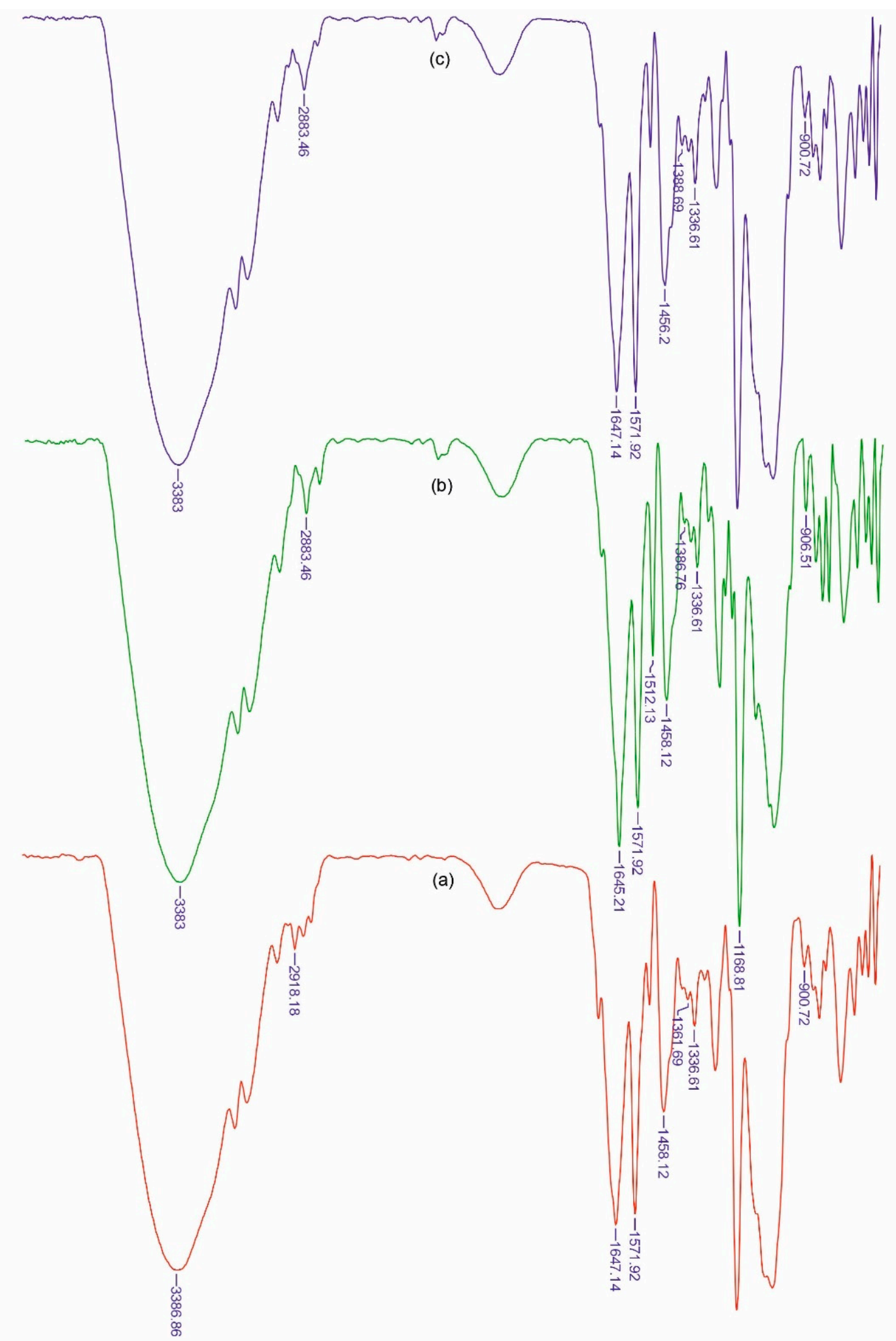

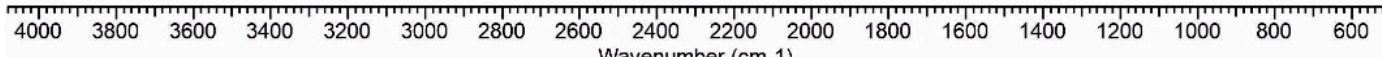
Wavenumber (cm-1)

Figure 2. FTIR spectra for CCPK (a), CCPOLK (b) and CCPLMCK (c). 


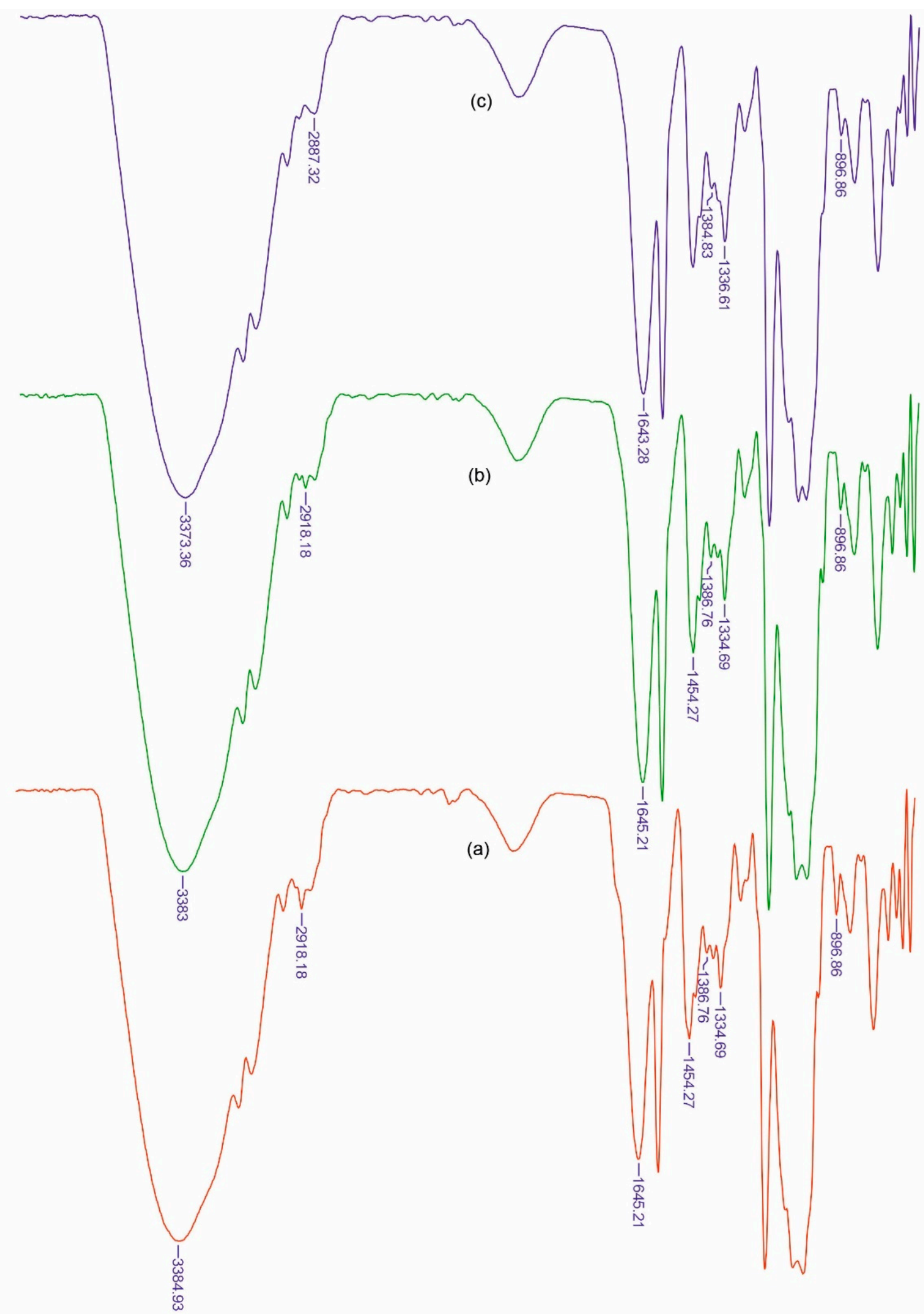

\begin{tabular}{llllllllllllllllll}
\hline 4000 & 3800 & 3600 & 3400 & 3200 & 3000 & 2800 & 2600 & 2400 & 2200 & 2000 & 1800 & 1600 & 1400 & 1200 & 1000 & 800 & 600
\end{tabular} Wavenumber (cm-1)

Figure 3. FTIR spectra for CCPLMCK(a), CCPOL (b) and CCP (c). 


\subsection{Mechanical Properties}

In order to examine the effect of fillers on the mechanical strength of biomaterials, CCP-based hydrogels with different fillers including lignin (OL), lignin hybrid (LMC), and/or ketoconazole (K) were prepared. Typical stress-strain compression curves are revealed for all hydrogel samples (Figure 4), and the values of the compressive Young's modulus and compressive strength of all hydrogels are depicted in Table 2. ANOVA (analysis of variance) test for all biocomposites was performed for a $5 \%$ confidence interval (alpha parameter was set to 0.05). $p$-value (0.001077) is less than the significance level (0.05); therefore, the null hypothesis (all materials have the same mechanical strength) is rejected. The Fisher parameter F (8.745) being larger than Fcrit (3.105) shows that there is a significant difference between the strength properties of the biomaterials in question, with CCPOL being a better candidate.
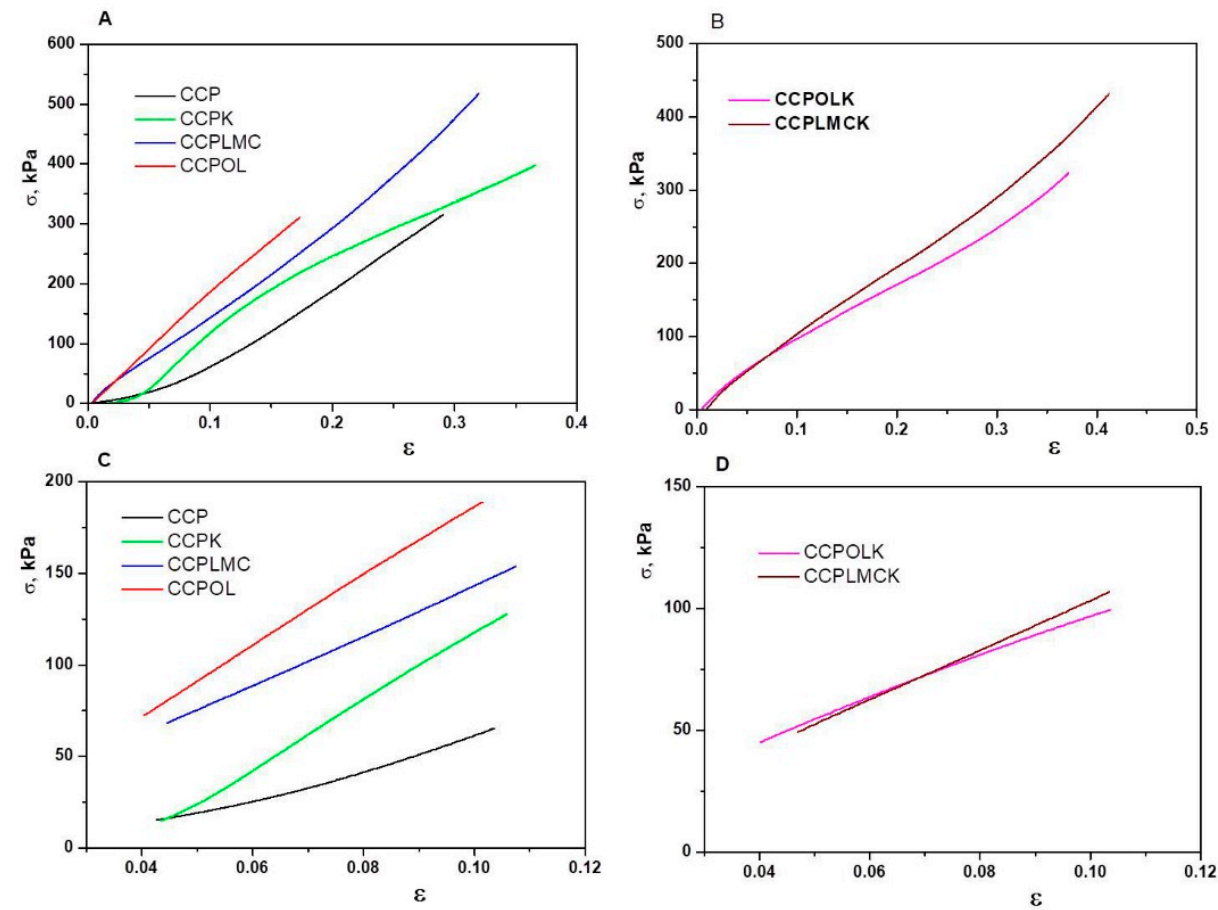

Figure 4. (A,B) Stress-strain curves obtained upon uniaxial compression onto swollen CCP-based hydrogels; (C,D) linear part of stress-strain curves from which the compressive Young's modulus of all hydrogel samples was calculated.

Table 2. Values of the compressive Young's modulus (E, MPa) and compressive strength of the swollen CCP-based hydrogels.

\begin{tabular}{|c|c|c|c|c|c|c|}
\hline Sample Code & $\mathrm{E}, \mathrm{kPa}$ & \multicolumn{3}{|c|}{ Compressive Strength, $\mathrm{kPa}$} & $\mathbf{R}^{2}$ & Variance \\
\hline $\mathrm{CCP}$ & $828 \pm 230$ & \multicolumn{3}{|c|}{$61.37 \pm 1.21$} & 0.989 & 52,900 \\
\hline CCPK & $1877 \pm 170$ & \multicolumn{3}{|c|}{$117.94 \pm 2.07$} & 0.999 & 28,900 \\
\hline CCPLMC & $1357 \pm 460$ & \multicolumn{3}{|c|}{$143.28 \pm 3.42$} & 0.999 & 211,600 \\
\hline CCPOL & $1928 \pm 280$ & \multicolumn{3}{|c|}{$186.58 \pm 4.29$} & 0.999 & 78,400 \\
\hline CCPLMCK & $1014 \pm 340$ & \multicolumn{3}{|c|}{$103.19 \pm 2.11$} & 0.999 & 115,600 \\
\hline CCPOLK & $856 \pm 140$ & \multicolumn{3}{|c|}{$96.78 \pm 1.36$} & 0.998 & 19,600 \\
\hline \multicolumn{7}{|c|}{ ANOVA (Analysis of Variance) } \\
\hline Source of Variation & SS & $\mathrm{df}$ & MS & $\mathrm{F}$ & $p$-value & F crit \\
\hline Between Groups & $3,695,034$ & 5 & $739,006.8$ & 8.745643 & 0.001077 & 3.105875 \\
\hline Within Groups & $1,014,000$ & 12 & 84,500 & & & \\
\hline
\end{tabular}


The CCP-based hydrogel without fillers exhibits weaker compressive mechanical strength with a value of the compressive Young's modulus of $0.828 \mathrm{MPa}$ and a compressive strength of $61.37 \mathrm{kPa}$ (Figure 3A,C and Table 2). With the addition of fillers in the hydrogel-based materials, the mechanical strength of the hydrogel formulations increased gradually. When the lignin hybrid (LMC), ketoconazole (K), or lignin (OL) were incorporated into CCP based hydrogels, the compressive Young's modulus was 1.63, 2.26, and 2.33 fold higher than those of CCP-based hydrogel without fillers (Table 2). The improvement of the compressive mechanical properties of the filler-loaded CCP hydrogels is well correlated with the HBI and LOI values which are higher for the filler-containing CCP hydrogels than for neat hydrogel (CCP without fillers). Similar behavior has been also reported for xanthan-based cryogels [53]. When second filler, i.e., ketoconazole (K), was incorporated within CCPLMC or CCPOL hydrogels, the values of the Young's modulus and compression strength were diminished. This result could be associated with the high LOI values obtained for these hydrogel samples, which indicate more rigid hydrogels, but the energy/force put on it cannot be transferred away in time. The cationic octa ( $\gamma$-chloroammoniumpropyl) silsesquioxane-chitosan-oxidized hydroxypropyl cellulose hydrogels [54] have been previously reported to present a comparable behavior with our CCP-based hydrogels.

\subsection{Bio-/Muco-Adhesivity Properties}

The biocomposites based on collagen/polyurethane/cellulose present a surface with adhesive properties. Adhesion of materials to the cutaneous tissue is an important property for product efficacy. In Table 3, the results are presented from bioadhesion and mucoadhesion tests on cellulose dialysis membrane and porcine skin, respectively.

Table 3. Adhesive properties of the studied materials.

\begin{tabular}{ccccc}
\hline \multirow{2}{*}{ Sample } & \multicolumn{2}{c}{ Bioadhesion Test } & \multicolumn{2}{c}{ Muchoadhesion Test } \\
\cline { 2 - 5 } & Adhesion Force $(\mathbf{N})$ & Total Work of Adhesion $(\mathbf{N} \times \mathbf{s})$ & Adhesion Force (N) & Total Work of Adhesion $(\mathbf{N} \times \mathbf{s})$ \\
\hline CCPK & $0.0588 \pm 0.00264$ & $0.0052 \pm 0.0004$ & $0.0555 \pm 0.00346$ & $0.00763 \pm 0.0006$ \\
\hline CCPOLK & $0.04409 \pm 0.00262$ & $0.00183 \pm 0.00046$ & $0.0627 \pm 0.0049$ & $0.00746 \pm 0.0007$ \\
\hline CCPLMCK & $0.0597 \pm 0.00195$ & $0.00576 \pm 0.00041$ & $0.0584 \pm 0.0113$ & $0.00736 \pm 0.00056$ \\
\hline
\end{tabular}

The mucoadhesion test was performed in order to measure the ability of the films to adhere onto the porcine skin. The mucin present in the mucus surface layer of porcine skin is rich in cysteine ( $>10 \%$ of the amino acids) and therefore in the thiol groups which can lead the formation of with organic lignin; thus, CCPOLK has the greatest mucoadhesion force. The total work of the adhesion values is in good agreement with those of the adhesive forces.

\subsection{In Vitro Release of Active Drug From Biocomposites}

The ketoconazole release profiles from the investigated materials were studied (Figure 4) to evaluate the potential delivery applications.

Comparing results presented in Figure 5 and Table 4, it seems that the highest amount of the active substance was released from CCPOLK material, which is in a good agreement with the findings regarding mucoadhesive properties (Table 3). For all samples, the correlation coefficient $\left(R^{2}\right)$ was rather high $(0.990)$ and describes the Korsmeyer-Peppas model. The transport constants $(k)$ and transport exponents $(n)$ were determined from the obtained data. 


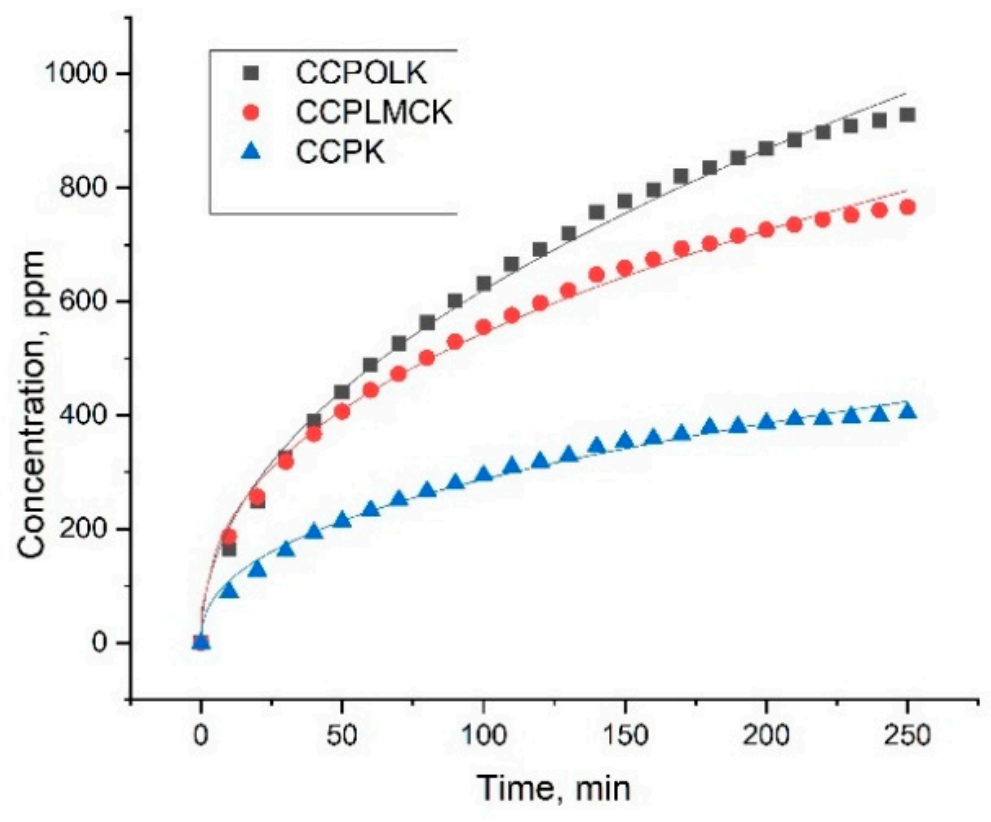

Figure 5. Release profiles of ketoconazole from the investigated samples.

Table 4. Kinetic parameters of the drug release from investigated samples.

\begin{tabular}{cccc}
\hline Samples & $\boldsymbol{n}$ & $\boldsymbol{k}, \boldsymbol{m i n}^{-\boldsymbol{n}}$ & $\mathbf{R}^{\mathbf{2}}$ \\
\hline CCPK & 0.424 & 40.54 & 0.990 \\
\hline CCPOLK & 0.484 & 66.38 & 0.994 \\
\hline CCPLMCK & 0.413 & 80.99 & 0.995 \\
\hline
\end{tabular}

$n=$ release exponent $k=$ release rate constant, $\mathrm{R}^{2}=$ correlation coefficient.

The $k$ value was higher for the CCPLMCK sample as compared to the CCPOLK sample. The value of $n$ was less than 0.5 for all samples, and this corresponds to a Fickian diffusion, suggesting that the release mechanisms of ketoconazole was related to the physical diffusion/drug dissolution interaction of electrostatic forces or hydrogen bonds [55].

\subsection{Antimicrobial Activity}

From Table 5, it is clear that all tested materials have biocidal activity. Note that CCPLMCK proves to be an active biomaterial against all three microorganisms, with an inhibition rate of $100 \%$.

Table 5. Antimicrobial activity for tested biocomposites.

\begin{tabular}{ccccccccccc}
\hline \multirow{2}{*}{ Sample } & \multicolumn{2}{c}{ ATCC 25,922 Escherichia coli } & \multicolumn{2}{c}{ Candida albicans $\mathbf{9 0 , 0 2 8}$} & \multicolumn{3}{c}{ Staphylococcus aureus 25,923 } \\
\cline { 2 - 11 } & $\begin{array}{c}\text { Initial Number } \\
\text { of Colonies }\end{array}$ & $\mathbf{2 4} \mathbf{h}$ & $\begin{array}{c}\text { Inhibition, } \\
\mathbf{\%}\end{array}$ & $\begin{array}{c}\text { Initial Number } \\
\text { of Colonies }\end{array}$ & $\mathbf{2 4} \mathbf{h}$ & $\begin{array}{c}\text { Inhibition, } \\
\mathbf{\%}\end{array}$ & $\begin{array}{c}\text { Initaial Number } \\
\text { of Colonies }\end{array}$ & $\begin{array}{c}\mathbf{2 4} \mathbf{h} \\
\text { Inhibition, } \\
\mathbf{\%}\end{array}$ \\
\hline Reference & 287 & 287 & 0 & 255 & 255 & 0 & 293 & 293 & 0 \\
\hline CCP & 287 & 3 & 99 & 255 & 183 & 28 & 293 & 11 & 96 \\
\hline CCPK & 287 & 0 & 100 & 255 & 23 & 91 & 293 & 6 & 98 \\
\hline CCPOL & 287 & 4 & 99 & 255 & 14 & 95 & 293 & 127 & 57 \\
\hline CCPOLK & 287 & 0 & 100 & 255 & 5 & 98 & 293 & 93 & 68 \\
\hline CCPLMC & 287 & 0 & 100 & 255 & 186 & 27 & 293 & 3 & 99 \\
\hline CCPLMCK & 287 & 0 & 100 & 255 & 0 & 100 & 293 & 0 & 100 \\
\hline
\end{tabular}




\subsection{Material's Morphology}

SEM images (Figure 6) can give important information about biocomposites morphology. When lignin or lignin-metal complex/ketoconazole were added into the matrix, its surface tends to become smoother. The presence of some microdomains suggested the development of hydrogen bonds network between matrix components and lignin/ketoconazole, in agreement with HBI value from Table 1.
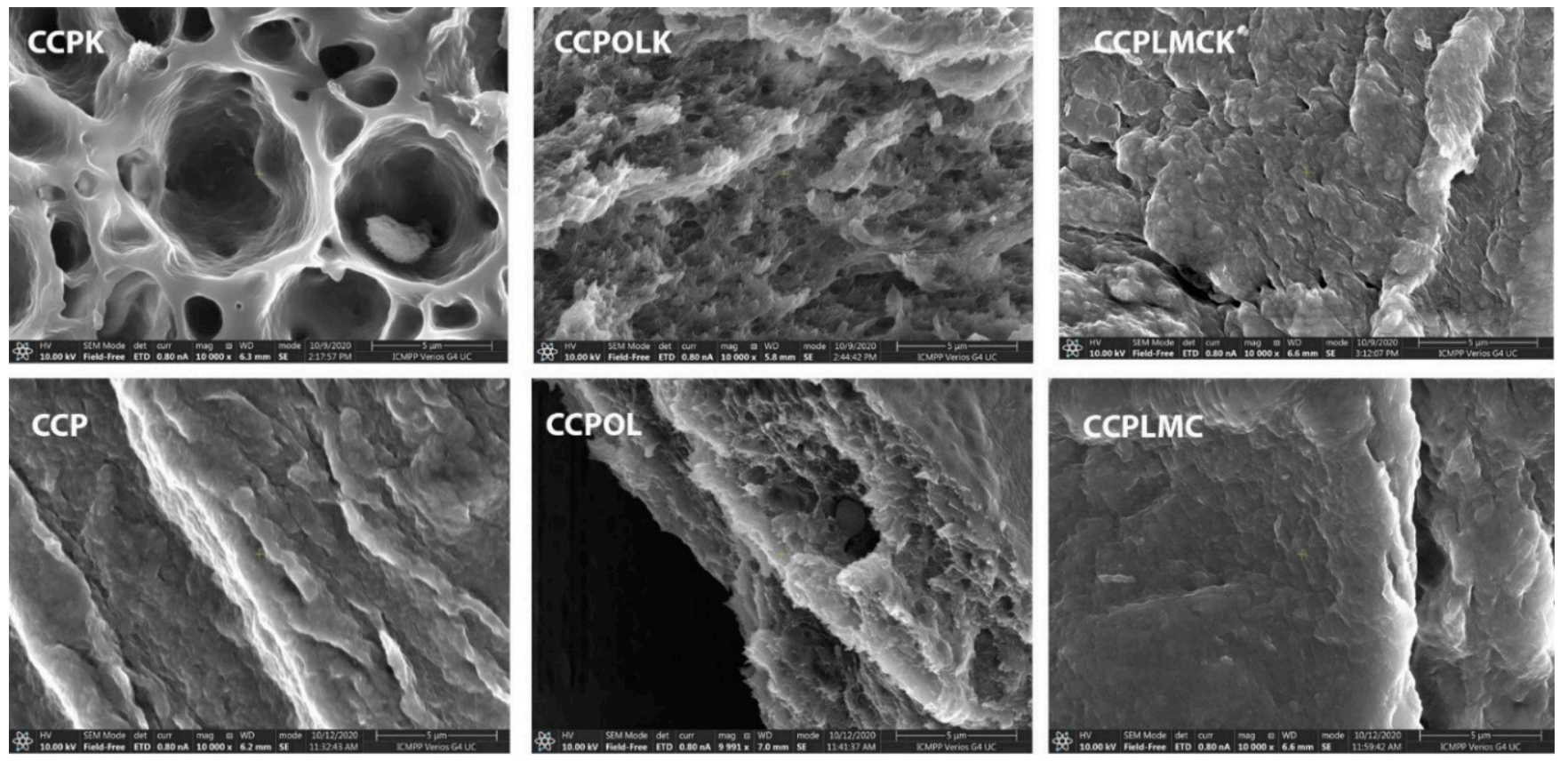

Figure 6. SEM images of the materials.

\section{Conclusions}

Collagen/polyurethane/cellulose-based composite materials that function as transcutaneous drug delivery systems have been developed. Doping the polymer matrix with lignin or lignin-metal complexes induces an increase in mechanical strength and gives composites a controlled drug release character as well as biocidal activity. Compressive strength and the elastic modulus of biocomposites comprising lignin or lignin lignin-metal complex were significantly enhanced; thus, the compressive strength increased from 61.37 to $186.5 \mathrm{kPa}$, while the elastic modulus increased from 0.828 to $1.928 \mathrm{MPa}$. The improvement of biological properties is also confirmed by the increase in mucoadhesivity. In vitro release of ketoconazole from the biocomposites is described by the KorsmeyerPeppas model with a Fickian diffusion. All materials tested were shown to be active against pathogenic microorganisms.

As a perspective, we have already considered the possibility of using these formulations in cosmetics, by introducing antioxidant substances in the base matrix.

Author Contributions: Conceptualization and methodology, N.A.; writing-original draft preparation, N.A.; writing and review, N.A.; editing, N.A.; investigation, N.A., V.M.D., L.V. and I.A.S. All authors have read and agreed to the published version of the manuscript.

Funding: This research received no external funding.

Institutional Review Board Statement: The study was conducted according to the guidelines of the Declaration of Helsinki, and approved by the Institutional Review Board (or Ethics Committee) of the University of Medicine and Pharmacy “Grigore T. Popa" Iasi, Romania (15186/2008).

Informed Consent Statement: Not applicable.

Conflicts of Interest: The authors declare no conflict of interest. 


\section{References}

1. Kaparekar, P.S.; Pathmanapan, S.; Anandasadagopan, S.K. Polymeric scaffold of Gallic acid loaded chitosan nanoparticles infused with collagen-fibrin for wound dressing application. Int. J. Biol. Macromol. 2020, 165, 930-947. [CrossRef]

2. Salamanca, E.; Hsu, C.C.; Yao, W.L.; Choy, C.S.; Pan, Y.H.; Teng, N.C.; Chang, W.J. Porcine Collagen-Bone Composite Induced Osteoblast Differentiation and Bone Regeneration In Vitro and In Vivo. Polymers 2020, 12, 93. [CrossRef]

3. Shah, R.; Stodulka, P.; Skopalova, K.; Saha, P. Dual Crosslinked Collagen/Chitosan Film for Potential Biomedical Applications. Polymers 2019, 11, 2094. [CrossRef]

4. Aki, D.; Ulag, S.; Unal, S.; Sengor, M.; Ekren, N.; Lin, C.C.; Yılmazer, H.; Ustundag, C.B.; Kalaskar, D.M.; Gunduz, O. 3D printing of PVA/hexagonal boron nitride/bacterial cellulose composite scaffolds for bone tissue engineering. Mater. Des. 2020, 196, 109094. [CrossRef]

5. Sangtarashani, S.M.H.; Rahmaninia, M.; Behrooz, R.; Khosravani, A. Lignocellulosic hydrogel from recycled old corrugated container resources using ionic liquid as a green solvent. J. Environ. Manag. 2020, 270, 110853. [CrossRef]

6. Xing, L.; Hu, C.; Zhang, W.; Guan, L.; Gu, J. Transition of cellulose supramolecular structure during concentrated acid treatment and its implication for cellulose nanocrystal yield. Carbohydr. Polym. 2020, 229, 115539. [CrossRef] [PubMed]

7. Cho, C.; Kobayashi, T. Advanced Cellulose Cosmetic Facial Masks Prepared from Myanmar Thanaka Heartwood. Curr. Opin. Green Sustain. 2021, 27, 100413. [CrossRef]

8. Bianchet, R.T.; Cubas, A.L.V.; Machado, M.M.; Moecke, E.H.S. Applicability of Bacterial Cellulose in Cosmetics—Bibliometric Review. Biotechnol. Rep. 2020, 27, e00502. [CrossRef] [PubMed]

9. Anghel, N.; Lazar, S.; Ciubotariu, B.I.; Verestiuc, L.; Spiridon, I. New cellulose-based materials as transdermal transfer systems for bioactive substances. Cellul. Chem. Technol. 2019, 53, 879. [CrossRef]

10. Spiridon, I.; Anghel, N.; Bele, A. Behavior of biodegradable composites based on starch reinforced with modified cellulosic fibers. Polym. Adv. Technol. 2015, 26, 1189-1197. [CrossRef]

11. Rassu, P.R. Observed outcomes on the use of oxidized and regenerated cellulose polymer for breast conserving surgery e A case series. Ann. Med. Surg. 2016, 5, 57-66. [CrossRef] [PubMed]

12. Franceschini, G.; Visconti, G.; Sanchez, A.M.; Leone, A.D.; Salgarello, M.; Masetti, R. Oxidized regenerated cellulose in breast surgery: Experimental model. J. Surg. Res. 2015, 198, 237-244. [CrossRef]

13. Laffleur, F.; Egeling, M. Evaluation of cellulose based patches for oral mucosal impairment. J. Drug Deliv. Sci. Technol. 2020, 58, 101839. [CrossRef]

14. Khamrai, M.; Banerjee, S.L.; Paul, S.; Samanta, S.; Kundu, P.P. Curcumin entrapped gelatin/ionically modified bacterial cellulose based self-healable hydrogel film: An eco-friendly sustainable synthesis method of wound healing patch. Int. J. Biol. Macromol. 2019, 122, 940-953. [CrossRef]

15. Muchová, M.; Münster, L.; Capáková, Z.; Mikulcová, V.; Kuřitka, I.; Vícha, J. Design of dialdehyde cellulose crosslinked poly(vinyl alcohol) hydrogels for transdermal drug delivery and wound dressings. Mater Sci. Eng. C 2020, 116, 111242. [CrossRef]

16. Taksitta, K.; Sujarit, P.; Rattanawimanwong, N.; Donpudsa, S.; Songsrirote, K. Development of tannin-immobilized cellulose fiber extracted from coconut husk and the application as a biosorbent to remove heavy metal ions. Environ. Nanotechnol. Monit. Manag. 2020, 14, 100389. [CrossRef]

17. Zhoua, H.; Zhua, H.; Xuea, F.; Hea, H.; Wang, S. Cellulose-based amphoteric adsorbent for the complete removal of low-level heavy metal ions via a specialization and cooperation mechanism. Chem. Eng. Technol. 2020, 385, 123879. [CrossRef]

18. Huang, X.; Wang, L.; Zhang, J.; Du, X.; Wu, S.; Wang, H.; Wei, X. A novel $\varepsilon$-polylysine-modified microcrystalline cellulose based antibacterial hydrogel for removal of heavy metal. Int. J. Biol. Macromol. 2020, 163, 1915-1925. [CrossRef]

19. Li, S.S.; Song, Y.L.; Yang, H.R.; An, Q.D.; Xiao, Z.Y.; Zhai, S.R. Carboxymethyl cellulose-based cryogels for efficient heavy metal capture: Aluminum-mediated assembly process and sorption mechanism. Int. J. Biol. Macromol. 2020, 164, 3275-3286. [CrossRef]

20. Choi, H.Y.; Bae, J.H.; Hasegawa, Y.; An, S.; Kim, I.S.; Lee, H.; Kim, M. Thiol-Functionalized Cellulose Nanofiber Membranes for the Effective Adsorption of Heavy Metal Ions in Water. Carbohydr. Polym. 2020, 234, 115881. [CrossRef]

21. Pooresmaeila, M.; Javanbakhta, S.; Niaa, S.B.; Namazi, H. Carboxymethyl cellulose/mesoporous magnetic graphene oxide as a safe and sustained ibuprofen delivery bio-system: Synthesis, characterization, and study of drug release kinetic. Colloids Surf. A 2020, 594, 124662. [CrossRef]

22. Kundu, D.; Banerjee, T. Development of microcrystalline cellulose based hydrogels for the in vitro delivery of Cephalexin. Heliyon 2020, 6, e03027. [CrossRef]

23. Abukhadraa, M.R.; Mohamed, A.S.; El-Sherbeenyd, A.M.; Nadeeme, A.; Ahmad, S.F. Synthesis of exfoliate bentonite/cellulose nanocomposite as a delivery system for Oxaliplatin drug with enhanced loading and release properties; cytotoxicity and pharmacokinetic studies. Chem. Phys. Lett. 2020, 755, 137818. [CrossRef]

24. George, D.; Maheswari, P.U.; Begum, M.S. Chitosan-cellulose hydrogel conjugated with L-histidine and zinc oxide nanoparticles for sustained drug delivery: Kinetics and in-vitro biological studies. Carbohydr. Polym. 2020, 236, 116101. [CrossRef] [PubMed]

25. Yang, X.; Jiang, X.; Yang, H.; Bian, L.; Chang, C.; Zhang, L. Biocompatible cellulose-based supramolecular nanoparticles driven by host-guest interactions for drug delivery. Carbohydr. Polym. 2020, 237, 116114. [CrossRef] [PubMed]

26. Zhang, W.; Wang, X.; Li, X.; Zhang, L.; Jiang, F. A 3D porous microsphere with multistage structure and component based on bacterial cellulose and collagen for bone tissue engineering. Carbohydr. Polym. 2020, 236, 116043. [CrossRef] 
27. Noha, Y.K.; Da Costa, A.D.S.; Parkd, Y.S.; Due, P.; Kimb, Y.H.; Park, K. Fabrication of bacterial cellulose-collagen composite scaffolds and their osteogenic effect on human mesenchymal stem cells. Carbohydr. Polym. 2019, 219, 210-218. [CrossRef]

28. Naureen, B.; Haseeb, A.S.M.A.; Basirun, W.J.; Muhamad, F. Recent advances in tissue engineering scaffolds based on polyurethane and modified polyurethane. Mat. Sci. Eng. C 2021, 118, 111228. [CrossRef]

29. Farzana, A.; Borandeha, S.; Ezazib, N.Z.; Lipponena, S.; Santosb, H.A.; Seppälä, J. 3D scaffolding of fast photocurable polyurethane for soft tissue engineering by stereolithography: Influence of materials and geometry on growth of fibroblast cells. Eur. Polym. J. 2020, 139, 109988. [CrossRef]

30. Ali, M.G.; Mousa, H.M.; Blaudez, F.; Abd El-sadek, M.S.; Mohamed, M.A.; Abdel-Jaber, G.T.; Abdal-hay, A.; Ivanovski, S. Dual Nanofiber Scaffolds Composed of Polyurethane- Gelatin/Nylon 6- Gelatin for Bone Tissue Engineering. Colloids. Surf. A 2020, 597, 124817. [CrossRef]

31. Kuźmińska, A.; Butruk-Raszeja, B.A.; Stefanowska, A.; Ciach, T. Polyvinylpyrrolidone (PVP) hydrogel coating for cylindrical polyurethane scaffolds. Colloids Surf. B 2020, 192, 111066. [CrossRef] [PubMed]

32. Liu, X.; Yan, B.; Hou, Z.; Zhang, N.; Gao, Y. A mild method for surface-grafting MPC onto poly(ester-urethane) based on aliphatic diurethane diisocyanate with high grafting efficiency. Mater. Sci. Eng. C 2019, 104, 109952. [CrossRef] [PubMed]

33. Hou, Z.; Xu, J.; Teng, J.; Jia, Q.; Wang, X. Facile preparation of medical segmented poly(ester-urethane) containing uniformly sized hard segments and phosphorylcholine groups for improved hemocompatibility. Mater. Sci. Eng. C 2020, $109,110571$. [CrossRef] [PubMed]

34. Zhang, L.; Zhang, C.; Zhang, W.; Zhang, H.; Hou, Z. Synthesis and properties of biodegradable poly(ester-urethane)s based on poly( $\varepsilon$ caprolactone) and aliphatic diurethane diisocyanate for long-term implant application: Effect of uniform-size hard segment content. J. Biomater. Sci. Polym. Ed. 2019, 30, 1212-1226. [CrossRef]

35. Yin, S.; Xi, Y.; Ji, Q.; Hou, Z.; Zhang, N. Preparation and properties of biomedical segmented polyurethanes based on poly(ether ester) and uniform-size diurethane diisocyanates. J. Biomater. Sci. Polym. Ed. 2017, 28, 119-138. [CrossRef] [PubMed]

36. Esmaeili, E.; Eslami-Arshaghi, T.; Hosseinzadeh, S.; Elahirad, E.; Jamalpoor, Z.; Hatamie, S.; Soleimani, M. The biomedical potential of cellulose acetate/polyurethane nanofibrous mats containing reduced graphene oxide/silver nanocomposites and curcumin: Antimicrobial performance and cutaneous wound healing. Int. J. Biol. Macromol. 2020, 152, 418-427. [CrossRef]

37. Jiang, B.; Chen, H.; Zhao, H.; Wu, W.; Jin, Y. Structural features and antioxidant behavior of lignins successively extracted from ginkgo shells (Ginkgo biloba L). Int. J. Biol. Macromol. 2020, 163, 694-701. [CrossRef]

38. Karmanov, A.P.; Kocheva, L.S.; Belyy, V.A. Topological structure and antioxidant properties of macromolecules of lignin of hogweed Heracleum sosnowskyi Manden. Polymer 2020, 202, 122756. [CrossRef]

39. Michelin, M.; Marques, A.M.; Pastrana, L.M.; Teixeira, J.A.; Cerqueira, M.A. Carboxymethyl cellulose-based films: Effect of organosolv lignin incorporation on physicochemical and antioxidant properties. J. Food Eng. 2020, 285, 110107. [CrossRef]

40. Rukmanikrishnan, B.; Ramalingam, S.; Rajasekharan, S.K.; Lee, J.; Lee, J. Binary and ternary sustainable composites of gellan gum, hydroxyethyl cellulose and lignin for food packaging applications: Biocompatibility, antioxidant activity, UV and water barrier properties. Int. J. Biol. Macromol. 2020, 153, 55-62. [CrossRef]

41. Gagini, T.; Colina-Vegas, L.; Villarreal, W.; Borba-Santos, L.P.; Souza Pereira, C.; Batista, A.Z.; Fleury, M.K.; Souza, W.; Rozental, S.; Costa, L.A.S.; et al. Metal-azole fungistatic drug complexes as anti-Sporothrix spp. Agents. New J. Chem. 2018, 42, 13641-13650. [CrossRef]

42. Mikkonen, H.; Peltonen, S.; Kallioinen, A.; Suurnäkki, A.; Kunnari, V.; Malm, T. Process for Defibering a Fibrous Raw-Material. WO2009066007, 2009-05-28 (FI20075823, EP2212469). Available online: https://patents.google.com/patent/WO2009066007A2 (accessed on 15 April 2021).

43. Spiridon, I.; Anghel, N.; Dinu, M.V.; Vlad, S.; Bele, A.; Ciubotaru, B.I.; Verestiuc, L.; Pamfil, D. Development and Performance of Bioactive Compounds-Loaded Cellulose/Collagen/Polyurethane Materials. Polymers 2020, 12, 1191. [CrossRef]

44. Korsmeyer, R.W.; Lustig, S.R.; Peppas, N.A. Solute and penetrant diffusion in swellable polymers. I. Mathematical modeling. J. Polym. Sci. Part B Polym. Phys. 1986, 24, 395-408. [CrossRef]

45. Ritger, P.L.; Peppas, N.A. A simple equation for description of solute release II. Fickian and anomalous release from swellable devices. J. Control. Release 1987, 5, 37-42. [CrossRef]

46. Rosa, M.F.; Medeiros, E.S.; Malmonge, J.A.; Gregorski, K.S.; Wood, D.F.; Mattoso, L.H.C.; Imam, S.H. Cellulose nanowhiskers from coconut husk fibers: Effect of preparation conditions on their thermal and morphological behavior. Carbohyd. Polym. 2010, 8, 83-92. [CrossRef]

47. Poletto, M.; Pistor, V.; Zeni, M.; Attera, A.J. Crystalline properties and decomposition kinetics of cellulose fibers in wood pulp obtained by two pulping processes. Polym. Degrad. Stabil. 2011, 96, 679-685. [CrossRef]

48. Xu, F.; Yu, J.; Tesso, T.; Dowell, F.; Wang, D. Qualitative and quantitative analysis of lignocellulosic biomass using Infrared Techniques: A mini-review. Appl. Energy 2013, 104, 801-809. [CrossRef]

49. Fackler, K.; Stevanic, J.S.; Ters, T.; Hinterstoisser, B.; Schwanninger, M.; Salmén, L. FTIR Imaging Spectroscopy to Localise and Characterise Simultaneous and Selective White-Rot Decay within Sprude Woodcell. Holzforschung 2011, 65, 411-420. [CrossRef]

50. Bonakdar, S.; Emami, S.H.; Shokrgozar, M.A.; Farhadic, A.; Ahmadi, S.A.H.; Amanzadeh, A. Preparation and characterization of polyvinyl alcohol hydrogels crosslinked by biodegradable polyurethane for tissue engineering of cartilage. Mater. Sci. Eng. C Mater. Biol. Appl. 2010, 30, 636-643. [CrossRef] 
51. Riaz, T.; Zeeshan, R.; Zarif, F.; Ilyas, K.; Muhammad, N.; Safi, S.Z.; Rahim, A.; Rizvi, S.A.A.; Rehman, I.U. FTIR analysis of natural and synthetic collagen. Appl. Spectrosc. Rev. 2018, 53, 703-746. [CrossRef]

52. Colom, X.; Carrillo, F. Crystallinity changes in lyocell and viscose-type fibres by caustic treatment. Eur. Polym. J. 2002, 38, 2225-2230. [CrossRef]

53. Raschip, I.E.; Fifere, N.; Varganici, C.D.; Dinu, M.V. Development of antioxidant and antimicrobial xanthan-based cryogels with tuned porous morphology and controlled swelling features. Int. J. Biol. Macromol. 2020, 156, 608-620. [CrossRef] [PubMed]

54. Zhang, X.; Meng, Y.; Shen, W.; Dou, J.; Liu, R.; Jin, Q.; Fang, S. pH-responsive injectable polysaccharide hydrogels with selfhealing, enhanced mechanical properties based on POSS. React. Funct. Polym. 2021, 158, 104773. [CrossRef]

55. Mandapalli, P.K.; Venuganti, V.V.K. Layer-by-layer microcapsules for $\mathrm{pH}$-controlled delivery of small molecules. J. Pharm. Investig. 2015, 45, 131-141. [CrossRef] 